\title{
Levantamento da produção sobre sociedade, cultura e Educação Física em periódicos brasileiros da Educação Física (1999-2019)
}

\author{
Survey of the production on society, culture and Physical Education in Brazilian Physical \\ Education journals (from 1999 to 2019)
}

Levantamiento de la producción sobre Sociedad, Cultura y Educación Física en revistas brasileñas de Educación Física (1999-2019)

Cristiano Mezzaroba ${ }^{\mathrm{I}}$, Lucas Vinicius Araujo Lisboa ${ }^{\mathrm{II}}$

\begin{abstract}
Resumo
O artigo apresenta um levantamento de dados que explicita a produção de conhecimento científico e pedagógico quando relacionamos a Educação Física (EF) brasileira aos aspectos sociais e culturais, evidenciando a aproximação do campo da EF aos conhecimentos das Ciências Humanas e Sociais. Assim, neste estudo, de natureza qualitativa e de caráter descritivo, do tipo documental, realizamos a identificação, quantificação e sistematização do volume de artigos e estudos encontrados nos periódicos brasileiros de EF, referentes ao período compreendido entre 1999 a 2019, os quais foram agrupados em 10 eixos temáticos. Também identificamos os principais agentes da EF brasileira que produzem e veiculam conhecimento pedagógico e sociocultural no campo da $\mathrm{EF}$, bem como, os principais pensadores sociais acionados pelos agentes brasileiros em suas publicações, o que torna possível a existência do conhecimento das Humanidades no contexto da EF, ampliando as condições de possibilidades investigativas, pedagógicas e formativas da EF brasileira.
\end{abstract}

Palavras-chave: Educação Física; Aspectos socioculturais; Produção do Conhecimento; Humanidades

\begin{abstract}
This article presents a data survey that explain the production of scientific and pedagogical knowledge when we relate Brazilian Physical Education (PE) to social and cultural aspects, showing the proximity of the field of PE to the knowledge of Human and Social Sciences. Thus, in this qualitative and descriptive study of a documentary type, we carried out the identification, quantification, and systematization of the volume of articles and studies found in Brazilian PE journals published from 1999 to 2019, which were grouped into 10 thematic axes. We also identified the main agents of Brazilian PE that produce and transmit pedagogical and socio-cultural knowledge in the field of $\mathrm{PE}$, as well as the main social thinkers triggered by Brazilian agents in their publications, which makes the existence of knowledge of the Humanities in the context of PE possible, expanding the conditions of investigative, pedagogical, and formative possibilities of the Brazilian PE.
\end{abstract}

Keywords: Physical Education; Sociocultural aspects; Knowledge production; Humanities

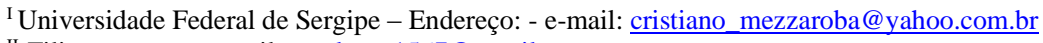

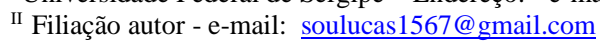




\section{Resumen}

El artículo presenta un levantamiento de datos que desvela la producción de conocimiento científico y pedagógico cuando relacionamos la Educación Física (EF) brasileña con aspectos sociales y culturales, mostrando la aproximación del campo de la EF al conocimiento de las Humanidades y Ciencias Sociales. Así, en este estudio cualitativo y descriptivo, de tipo documental, realizamos la identificación, cuantificación y sistematización del volumen de artículos y estudios encontrados en las revistas brasileñas de EF referido al período de 1999 hasta 2019, los cuales se agruparon en 10 ejes temáticos. También identificamos a los principales agentes de la EF brasileña que producen y difunden conocimientos pedagógicos y socioculturales en el campo de la EF, así como los principales pensadores sociales activados por los agentes brasileños en sus publicaciones, lo que posibilita la existencia del conocimiento de las Humanidades en el contexto de la EF, ampliando las condiciones de las posibilidades investigativas, pedagógicas y formativas de la EF brasileña.

Palabras clave: Educación Física; Aspectos socioculturales; Producción de conocimiento; Humanidades

\section{Introdução}

Ao longo de sua história, a Educação Física brasileira passou, e vem passando, por variados contextos de influências e práticas, desde o higienismo biomédico às práticas militares (e suas influências na disciplinarização dos corpos), passando pela presença constante dos determinantes esportivos (prática, treinamento, mercadorização e espetacularização), chegando aos aspectos pedagógicos/ educacionais. (BRACHT, 2001; PAIVA, 2003)

Com o processo de redemocratização do Brasil, nos anos 1980, e a conjuntura social, política e científica brasileira naquele momento, de abertura política; muitos pesquisadores pautaram seus estudos de pós-graduação fora das matrizes das áreas biológicas da EF, aproximando-se dos saberes e práticas das ciências humanas e sociais (CHSO). Ao retornarem com tais conhecimentos ao campo da EF (CEF), geraram-se "turbulências" que, passados mais de 30 anos, as vemos constantemente presentes no interior desse campo.

Uma das obras que evidenciaram essa abordagem "nova" entre Educação Física e Ciências humanas é o livro organizado por Yara Maria de Carvalho e Katia Rubio (2001), aproximando do CEF as abordagens da Antropologia, da Educação, da Filosofia, da História, da Psicologia e da Sociologia.

A partir dessa aproximação de fundamentos teórico-conceituais vinculados às ciências sociais, há maior amplitude de aproximações e interpretações teóricas quando as colocamos em interface com a EF, o que nos revela uma necessidade de aglutinar na formação acadêmica elementos interdisciplinares, responsáveis por promover o acesso a leituras críticas, reflexivas e criativas de mundo, permitindo, quiçá, uma ampliação da trajetória formativa do profissional. 
Dessa forma, diante dessa contextualização, perguntamo-nos: como podemos analisar a produção brasileira do $\mathrm{CEF}$, que vem tematizando saberes e práticas que se relacionam enfaticamente com os conhecimentos das CHSO (especialmente com a Sociologia e com a Antropologia)?

Nesta pesquisa, portanto, nosso objetivo foi identificar e analisar os artigos publicados nos principais periódicos científicos da EF brasileira, no período de 1999 a 2019, que trouxeram a discussão quanto aos termos sociedade, cultura e EF, em que procuramos aglutinar os dados a partir de eixos interpretativos.

Assim, além de identificar e quantificar a produção do conhecimento no CEF brasileira, este trabalho também tivemos como intento identificar os principais agentes desse campo que produzem e veiculam conhecimento pedagógico e sociocultural nesse lócus científico.

A realização de uma pesquisa como esta, de levantamento da produção, justifica-se pela importância acadêmico-científica em se compreender o próprio processo do "fazer acadêmico" em relação ao movimento da EF brasileira, de aproximação com as CHSO, permitindo, depois de algumas décadas (se considerado o chamado "Movimento Renovador da EF brasileira", dos anos finais da década de 1980), visualizar e analisar suas limitações e apontar possibilidades de trabalho investigativo e pedagógico que articule saberes e práticas da EF numa perspectiva sociocultural e pedagógica.

\section{Procedimentos Metodológicos}

A pesquisa, de natureza qualitativa, caracteriza-se metodologicamente pelo seu caráter exploratório (TRIVIÑOS, 1995), do tipo levantamento de dados quanti e qualitativos, sendo uma pesquisa documental (GIL, 1996).

Como fonte de dados, portanto, tivemos periódicos científicos da EF brasileira, que, segundo o estrato de qualificação Qualis da CAPES, estão compreendidos entre A2 e B5 (lembrando que não há nenhuma revista brasileira de EF com estrato A1 e, também, estima-se que há, no Brasil, em torno de 30 periódicos específicos da $\mathrm{EF}$, sendo que, para esta amostra, foram consideradas 12 revistas, segundo o critério exposto).

Consideramos o período temporal de 1999 a 2019, ou seja, os últimos 20 anos de produção deste conhecimento, tendo como critérios de inclusão os termos "sociedade", "cultura" e "Educação Física" nos títulos e/ ou resumos e/ ou palavras-chave. Compreendemos a possibilidade de o termo "sociedade" 
vincular-se ao conhecimento da Sociologia; de o termo "cultura" possibilitar vínculos com a Antropologia, os dois, ou cada um, sempre associados à produção do conhecimento que envolve a EF brasileira.

Partimos do pressuposto de que a pesquisa é um processo em que é impossível prever todas as etapas, como nos ensina Goldenberg (2005), e sabedores de que pesquisar é um exercício de constantes ajustes, adaptações, flexibilidade e adequação, acreditamos que a perspectiva heurística, da descoberta, norteou esta investigação, enquanto dimensão qualitativa e com objetivos descritivos. E, nesse sentido, pensamos ser possível considerarmos que "descobrimos" uma dimensão da EF brasileira que nos permite visualizá-la, a partir de agora, com mais elementos sobre seus modos de produção e de circulação de conhecimentos socioculturais e pedagógicos.

\section{Apresentando e discutindo a produção sociocultural e pedagógica da EF brasileira de 1999 a 2019}

Dessa forma, apresentamos, a partir de agora, o que denominamos como "mapas interpretativos"”, das relações que envolvem os saberes da Sociologia e da Antropologia com a EF. Trazemos, inicialmente, uma breve explicação sobre aspectos de inclusão e exclusão em relação aos textos encontrados. No caso das exclusões, foram retirados artigos em que os termos contidos em determinado texto não estavam condizentes com o foco da pesquisa (e, assim, excluímos resenhas, entrevistas e menções extrínsecas aos termos indexados). Já as inclusões foram feitas a partir dos termos diretamente envolvidos com o objetivo da pesquisa (EF, Sociedade, Cultura, Sociologia, Sociocultural, Antropologia, Etnografia). A partir dos procedimentos metodológicos mencionados, foi possível chegar ao seguinte quadro geral:

Quadro 1: Quantitativo de textos sobre EF, sociedade e cultura em periódicos brasileiros de EF (1999 a 2019)

\begin{tabular}{|c|c|c|c|c|c|c|c|}
\hline \multirow{2}{*}{ PERIÓDICO } & WEB & \multicolumn{2}{|c|}{ DADOS INICIAIS } & \multicolumn{2}{c|}{ DADOS DEPURADOS } & \multicolumn{2}{|c|}{ TOTAL $^{2}$} \\
\cline { 3 - 7 } & QUALIS & SOCIEDADE & CULTURA & SOCIEDADE & CULTURA $_{n}$ & \multicolumn{2}{c}{213} \\
\hline Movimento & A2 & 234 & 141 & 133 & 80 & 367 & 26 \\
\hline Motrivivência & B2 & 135 & 73 & 27 & 208 & 53 \\
\hline $\begin{array}{c}\text { R. Brasileira } \\
\text { de Ciência do } \\
\text { Esporte }\end{array}$ & B1 & 42 & 26 & 27 & 18 & 68 & 45 \\
\hline
\end{tabular}

\footnotetext{
${ }^{1}$ No mesmo sentido mobilizado em Mezzaroba (2018), um modo de organização e sistematização dos dados oriundos da análise documental, neste caso, que permitiu organizar, sistematizar, explicitar e clarificar o conjunto dos dados coletados das revistas selecionadas, como exposto no Quadro 2.

${ }^{2}$ Em relação aos quantitativos expostos no Quadro 1, informamos que os valores contidos na coluna da esquerda do total referem-se ao total dos textos com menção à sociedade e cultura encontradas inicialmente $(234$, Sociedade +141 , Cultura $=375-$ lembrando que, pelos critérios de exclusão, chegou-se ao total de 367), e os dados da coluna da direita referem-se ao total desses textos que foram incluídos na pesquisa, como dados depurados $(153$, Sociedade +80 , Cultura $=213)$.
} 


\begin{tabular}{|c|c|c|c|c|c|c|c|}
\hline $\begin{array}{l}\text { R. Brasileira } \\
\text { de EF e } \\
\text { Esporte }\end{array}$ & B1 & 80 & 30 & 29 & 15 & 110 & 44 \\
\hline Motriz & B1 & 35 & 30 & 20 & 16 & 65 & 36 \\
\hline $\begin{array}{c}\text { Revista EF } \\
\text { UEM }\end{array}$ & B1 & 33 & 68 & 13 & 19 & 101 & 32 \\
\hline $\begin{array}{c}\text { Pensar a } \\
\text { Prática }\end{array}$ & B2 & 74 & 64 & 12 & 18 & 138 & 30 \\
\hline Licere & B2 & 61 & 147 & 11 & 12 & 208 & 23 \\
\hline $\begin{array}{l}\text { R. Brasileira } \\
\text { de Ciência e } \\
\text { Movimento }\end{array}$ & B2 & 69 & 35 & 11 & 10 & 104 & 21 \\
\hline Mackenzie $^{3}$ & B3 & \multicolumn{2}{|c|}{409} & 10 & 9 & 409 & 19 \\
\hline Kinesis & B4 & 20 & 21 & 6 & 8 & 41 & 14 \\
\hline $\begin{array}{c}\text { R. Brasileira } \\
\text { de Atividade } \\
\text { Física e Saúde }\end{array}$ & B2 & 51 & 2 & 9 & 1 & 53 & 10 \\
\hline \multicolumn{6}{|c|}{ Total de textos encontrados } & 2047 & 540 \\
\hline
\end{tabular}

Fonte: Organizado pelos autores.

Como explicado anteriormente, utilizamos como critérios de exclusão a retirada de materiais como entrevistas, resenhas, relatos de experiência e menções que não considerassem os termos "Educação Física" com "sociedade", "cultura" e suas extensões, acima mencionadas (por isso, por exemplo, se considerarmos a Revista Movimento, a primeira da lista, o total de dados iniciais, 367, é um quantitativo menor, quando somamos 234 textos dos dados iniciais quanto à sociedade, e, dos 141 textos dos dados iniciais quanto à cultura - seriam 375 textos, mas consideramos 367, sendo excluídos, portanto, 8 textos - o que pode ser visualizado com outros periódicos e seus totais).

De maneira geral, a partir dos dados do Quadro 1, é possível observar um grande volume na produção sociocultural veiculada à $\mathrm{EF}$, o que nos mostra que, apesar do objeto de estudo comumente vinculado à EF ser aquele de viés biológico, o panorama da produção sociocultural no interior da EF indica haver uma ampliação da sua especificidade, implicando maiores possibilidades na área em relação à pesquisa, formação e atuação. Dessa maneira, pode-se afirmar que o conhecimento operado permite compreender a diversidade que envolve os mais diversos padrões culturais vinculados à EF brasileira. A partir da análise de dados realizada, organizamos, em nosso mapa interpretativo, as questões relacionadas à produção do conhecimento, quanto aos termos sociedade, cultura e EF.

${ }^{3}$ Salientamos que durante o processo de coleta de dados, na Revista Mackenzie, não foi possível utilizarmos os operadores booleanos, necessitando, assim, ler cada uma das publicações da revista, de 2002 a 2016 (período disponível de publicações, sendo que de 2016 até 2019 não há edições publicadas) para então conseguir extrair os dados necessários da pesquisa. 
É importante salientar que não fizemos um agrupamento total de textos relacionados a toda produção da EF brasileira a fim de comparativos iniciais, mas a partir dos dados de 2047 textos iniciais, o que indica um grande volume de produção, e, a partir da nossa seleção de inclusão relacionada à "sociedade", "cultura" e "Educação Física", foi possível chegar aos dados que nos permitiram criar os eixos interpretativos e que explicitam a produção científica sociocultural dessas últimas décadas.

Segundo Stigger (2015), um fato que merece destaque em relação à veiculação das CHSO na EF brasileira é que, a partir da década de 1980, ocorreu de forma intensa a apropriação de pesquisas e métodos oriundos destas áreas, o que permitiu um intenso e criativo desenvolvimento de investigações científicas nos últimos anos, já que, antes desse movimento, as pesquisas teóricas na EF quase majoritariamente se resumiam a análises quantitativas e mensurações no plano puramente biológico.

Visualizamos que a Revista Movimento (213 artigos publicados) e Motrivivência (53 artigos publicados) aparecem com maior produção veiculada às CHSO, o que condiz com seus escopos, já que ambas são declaradamente periódicos socioculturais, reafirmando que, dentro do CEF, há veículos que publicam exclusivamente esse tipo de conhecimento sociocultural. Entretanto, é possível observar que há poucas revistas que privilegiem publicações socioculturais e pedagógicas, existindo uma variedade maior de periódicos que privilegiam publicações de ordem biológica/ biomédica, que não levam em consideração fatores fundamentais para a análise da EF por outras "lentes" de leitura do mundo.

Por conseguinte, ao realizarmos a depuração e análise dos artigos encontrados, foi possível chegar àquilo que estamos denominando como "eixos temáticos", totalizando 10 eixos, os quais apontam concretude à nossa hipótese de pesquisa, de que há um movimento de pesquisadores que vêm produzindo conhecimento relacionado à área sociocultural e pedagógica, na tentativa de maior consolidação do CEF.

No Quadro 2 abaixo organizamos uma síntese quanti/qualitativa referente aos 540 artigos selecionados em torno dos eixos temáticos da produção identificada:

Quadro 2: Eixos temáticos a partir do levantamento realizado

\begin{tabular}{|c|l|c|}
\hline Eixo Temático & \multicolumn{1}{|c|}{ Descrição da Temática } & Quantitativo \\
\hline Esporte & $\begin{array}{l}\text { Artigos contêm uma visão técnica, sociológica, antropológica e } \\
\text { pedagógica em questões que envolvem a dimensão do esporte } \\
\text { como objeto do conhecimento. }\end{array}$ & 111 \\
\hline Corpo e cultura & $\begin{array}{l}\text { Produções relacionadas ao corpo, em seus sentidos, e atribuições } \\
\text { na relação dialética entre natureza, sociedade e cultura, } \\
\text { evidenciando também questões relacionadas à religião, à dança e } \\
\text { à saúde. }\end{array}$ & 75 \\
\hline
\end{tabular}




\begin{tabular}{|c|c|c|}
\hline Mídia & $\begin{array}{l}\text { Possibilidades de conteúdos da cultura corporal do movimento, } \\
\text { veiculados à mídia, sugerindo problematizações no ambiente de } \\
\text { atuação docente, favorecendo a construção de diversas estratégias } \\
\text { que envolvem mídias/ tecnologias. }\end{array}$ & 62 \\
\hline EF Escolar & $\begin{array}{l}\text { Textos têm como centralidade o contexto escolar, o conhecimento } \\
\text { de que trata o âmbito da didática da } \mathrm{EF} \text {, ou seja, a relação com a } \\
\text { lógica formal de apreensão do saber. }\end{array}$ & 51 \\
\hline Inclusão & $\begin{array}{l}\text { Eixo de inclusão de crianças a partir das mais diversas } \\
\text { nomenclaturas ("necessidades especiais", "pessoa com } \\
\text { deficiência", "deficiente físico", "deficiente mental" e "deficiente } \\
\text { visual") em relação ao contexto da prática pedagógica da EF, } \\
\text { visando uma maior participação nas aulas. }\end{array}$ & 49 \\
\hline Ludicidade & $\begin{array}{l}\text { Artigos que buscam compreender as brincadeiras e as } \\
\text { manifestações vivenciadas no ambiente escolar e familiar, sob a } \\
\text { perspectiva do cotidiano infantil, enfatizando as maneiras pelas } \\
\text { quais as crianças constroem suas impressões de corpo (dentro e } \\
\text { fora da escola). }\end{array}$ & 47 \\
\hline $\begin{array}{l}\text { Produção } \\
\text { Cientifica } \\
\text { Sociocultural e } \\
\text { Pedagógica }\end{array}$ & $\begin{array}{l}\text { Produção científica no contexto da EF, cujo foco se refere aos } \\
\text { aspectos culturais, sociológicos e pedagógicos pelos agentes da } \\
\text { EF. }\end{array}$ & 40 \\
\hline Gênero & $\begin{array}{l}\text { Textos que tematizam aspectos relacionados ao papel das } \\
\text { mulheres (com destaque para as representações e papéis sociais } \\
\text { que lhes são tradicionalmente concedidos), da masculinidade e } \\
\text { feminilidade, além de questões relacionadas à presença do público } \\
\text { LGBTQIA+ na EF. }\end{array}$ & 38 \\
\hline $\begin{array}{l}\text { Formação de } \\
\text { Professores e } \\
\text { Metodologias }\end{array}$ & $\begin{array}{l}\text { Eixo averigua as características do conhecimento empregado pelo } \\
\text { professor de EF em sua atuação, de como são guiados pelos } \\
\text { valores e normas, construídos antes mesmo da mediação do } \\
\text { Ensino Superior. }\end{array}$ & 36 \\
\hline $\begin{array}{c}\text { Políticas Públicas } \\
\text { e Lazer }\end{array}$ & $\begin{array}{l}\text { Textos cujo foco são as políticas públicas de esporte e lazer, com } \\
\text { reflexões, conceitos e procedimentos metodológicos, que } \\
\text { constituem parte fundamental das ferramentas de investigação do } \\
\text { pesquisador social, particularmente aqueles que buscam uma } \\
\text { leitura sociocultural do esporte, do lazer e das temáticas correlatas. }\end{array}$ & 31 \\
\hline
\end{tabular}

Fonte: Organizado pelos autores.

Ao analisarmos detalhadamente este quadro, relacionado à veiculação pedagógica que a EF possui, é possível observar uma grande produção de conhecimento sociocultural e pedagógico agrupada em diferentes temáticas, comprovando que o CEF sempre esteve em construção e renovação, ou seja, está em constante transformação nas duas últimas décadas. Entretanto, é necessário salientar que esse movimento de crescimento quanto às questões sociais e culturais é impulsionado por autores(as) que, especialmente desde a década de 1980, vêm firmando a necessidade de pensar e aproximar a EF com as Humanidades.

Também, é preciso considerar, a partir das observações de Hallal e Melo (2017), que há uma ambiguidade visível ao CEF brasileira, ou seja, quantitativamente o campo cresce, mas qualitativamente, há um enfraquecimento: 
O fato é que o cenário atual nos apresenta uma área muito fragmentada, composta por subáreas diversas que pouco interagem. Observa-se também uma cada vez mais comum migração (e não somente diálogo) de pesquisadores oriundos da Educação Física ligados às ciências humanas e sociais para outros campos de conhecimento (especialmente Educação, Ciências Sociais, História, Comunicação) (HALLAL; MELO, 2017, p. 325).

Se é sabido que as relações da EF com o esporte são históricas e muito próximas, o levantamento confirma tal aproximação, já que o eixo "Esporte" apresentou-se com a maior quantidade de textos encontrados, evidenciando que tal temática, há muitas décadas, “confunde-se” com a própria EF, não só escolar, mas também no senso comum, e que, com a intensificação da mercadorização e espetacularização, o esporte passou a ser algo que ganhou relevância social. E isso, inclusive hoje, muitas vezes, juntamente com a relevância atribuída à saúde, justifica a EF na escola, ou seja, as aulas de EF entendidas como momento de praticar/ aprender esporte.

Segundo Lovisolo, Vendrusculo e Góis Junior (2015), houve, no período referente à década de 1980, uma (des)biologização da EF, por meio do crescimento de pesquisas ancoradas em matrizes provenientes das CHSO, especialmente veiculadas à História, Antropologia e Sociologia. Assim, por meio da expansão de outras áreas de conhecimento, foi possível observar (conforme Quadro 2) que as temáticas relacionadas à cultura e sociedade ganharam destaque no CEF.

A partir da leitura de cada um dos textos, selecionados previamente em cada periódico, agrupamos os textos por eixo temático, devido à larga escala de artigos e informações que cada texto continha e, a partir disso, criamos um resumo que contemplou, de forma geral os conteúdos encontrados a partir da análise minuciosa de cada um dos artigos. Entretanto, em cada uma das temáticas, foi possível encontrar uma multiplicidade de facetas em torno das problemáticas, o que faz com que esse campo acadêmico e profissional mantenha uma constante dinâmica de discussões e abordagens.

Nessa perspectiva, ao trazermos exemplos de cada eixo temático, foi possível encontrar agentes da EF que se dedicam a produzir conhecimento no âmbito das CHSO, e que construíram, a partir da sua percepção e subjetividades quanto a fatores vistos, outrora, sob as "lentes" apenas biológicas, uma criação e uma renovação que se revelam pelos eixos temáticas aqui apresentados, evidenciando uma diversa produção sociocultural. Assim, no Quadro 3, identificamos também os principais agentes que se dedicam academicamente a esse tipo de produção do conhecimento, considerando o critério de recorrência de menções a esses nomes nos textos identificados e analisados:

Quadro 3: Agentes da EF brasileira que produzem e veiculam conhecimento sociocultural

\begin{tabular}{|c|c|c|}
\hline $\begin{array}{c}\text { Valter Bracht } \\
\text { (UFES) }\end{array}$ & $\begin{array}{c}\text { Hugo R. Lovisolo } \\
\text { (UERJ) }\end{array}$ & $\begin{array}{c}\text { Vicente Molina Neto } \\
\text { (UFRGS) }\end{array}$ \\
\hline
\end{tabular}




\begin{tabular}{|c|c|c|}
\hline $\begin{array}{c}\text { Jocimar Daolio } \\
\text { (UNICAMP) }\end{array}$ & $\begin{array}{c}\text { Giovani de L. Pires } \\
\text { (UFSC) }\end{array}$ & $\begin{array}{c}\text { Omar Schneider } \\
\text { (UFES) }\end{array}$ \\
\hline $\begin{array}{c}\text { Celi N. Z. Taffarel } \\
\text { (UFBA) }\end{array}$ & $\begin{array}{c}\text { Elenor Kunz } \\
\text { (UFSM) }\end{array}$ & $\begin{array}{c}\text { Helena Altmann } \\
\text { (UNICAMP) }\end{array}$ \\
\hline $\begin{array}{c}\text { Yara Maria de Carvalho } \\
\text { (USP) }\end{array}$ & $\begin{array}{c}\text { Silvana Goellner } \\
\text { (UFRGS) }\end{array}$ & $\begin{array}{c}\text { Carmen L. Soares } \\
\text { (UNICAMP) }\end{array}$ \\
\hline $\begin{array}{c}\text { Mauro Betti } \\
\text { (UNESP) }\end{array}$ & $\begin{array}{c}\text { Ivan M. Gomes } \\
\text { (UFES) }\end{array}$ & $\begin{array}{c}\text { Amauri A. B. de Oliveira } \\
\text { (UEM) }\end{array}$ \\
\hline $\begin{array}{c}\text { Felipe Q. de Almeida } \\
\text { (UFES) }\end{array}$ & $\begin{array}{c}\text { Alexandre F. Vaz } \\
\text { (UFSC) }\end{array}$ & $\begin{array}{c}\text { Ari Lazzarotti Filho } \\
\text { (UFG) }\end{array}$ \\
\hline $\begin{array}{c}\text { Suraya C. Darido } \\
\text { (UNESP) }\end{array}$ & $\begin{array}{c}\text { Victor A. de Melo } \\
\text { (UFRJ) }\end{array}$ & $\begin{array}{c}\text { Katia Rubio } \\
\text { (USP) }\end{array}$ \\
\hline $\begin{array}{c}\text { Marcos G. Neira } \\
\text { (USP) }\end{array}$ & $\begin{array}{c}\text { Wanderley Marchi Junior } \\
\text { (UFPR) }\end{array}$ & $\begin{array}{c}\text { Martha B. da Costa } \\
\text { (UNEB) }\end{array}$ \\
\hline $\begin{array}{c}\text { Marco Paulo Stigger } \\
\text { (UFRGS) }\end{array}$ & $\begin{array}{c}\text { Alex Branco Fraga } \\
\text { (UFRGS) }\end{array}$ & $\begin{array}{c}\text { Tarcísio Mauro Vago } \\
\text { (UFMG) }\end{array}$ \\
\hline
\end{tabular}

Fonte: Organizado pelos autores.

Ao identificarmos os principais agentes da EF brasileira, e o interesse pautado em tornar possível a associação dos conhecimentos sociológicos e antropológicos ao contexto da EF, visualizamos a possibilidade de ampliar a produção do conhecimento no que tange o CEF. Esse fator nos fez compreender esse movimento multifacetado na produção de conhecimento da área, através das contribuições que esses agentes, por meio das suas produções, trouxeram para o meio acadêmico e possíveis implicações ao contexto escolar e não escolar.

Destacamos que os(as) agentes listados no Quadro 3 foram incluídos e considerados imersos ao campo sociocultural e pedagógico da EF brasileira, a partir de leitura e análise dos artigos contidos nos periódicos, tornando-se recorrentes em publicações e menções, pois foram mencionados entre 9 a 14 vezes nas publicações, em diferentes obras e contribuições destes para o campo científico.

Aprendemos com Bourdieu, em relação ao seu conceito de campo, e ampliando o debate quanto ao campo científico, que o pano de fundo dessa questão está na luta científica por legitimação no interior do próprio campo, ou seja, tais movimentações e produções explicitam o jogo da luta científica, entendendo o campo como espaço de conflitos entre os dominantes, que almejam a conservação, e “[...] Estão comprometidos com a estrutura consolidada do campo e são os defensores habituais da <<ciência normal〉> do momento" (BOURDIEU, 2001, p. 55), e os dominados, que lutam pela sua transformação, levantando a seguinte questão: “[...] podemos perguntar-nos como são possíveis verdadeiras transformações do campo, uma vez que as forças do campo tendem a consolidar as posições dominantes [...]” (BOURDIEU, 2001, p. $55)$. 
Com isso, podemos ver que, se os autores mencionados acima são vinculados à produção de saberes socioculturais e pedagógicos, eles são "dominados” em relação ao campo biodinâmico da EF brasileira, pois há uma predominância maior na veiculação de artigos, análises e periódicos ligados às Ciências Biológicas, o que fez com que este meio de atuação estivesse "dominando" o pensamento relacionado à produção científica e à própria especificidade da EF, o que reduziu, por muitos anos, a potencialidade que a EF poderia almejar com sua aproximação e imersão com as Humanidades.

Sobre esses processos sócio-históricos do CEF brasileira, Paiva (1994) comenta quanto às "permanências no campo da EF brasileira":

[...] por essa época, entre 1985 e 1989, que instalou-se uma categorização esdrúxula no senso-comum da comunidade acadêmica da EF: seus profissionais passaram a ser classificados em 'tecnicistas $\mathrm{x}$ humanistas', 'conservadores $\mathrm{x}$ transformadores (ou progressistas)', 'positivistas $\mathrm{x}$ marxistas', 'teóricos $\mathrm{x}$ práticos', numa patente incompreensão do trabalho (científico) de teorizar. Ainda que estas questões digam respeito a toda a comunidade e, por isso, não tenham merecido investigação no âmbito dessa pesquisa, sua constatação parece precisa na medida em que apontaram para a reordenação acadêmica que esboçou-se na década de 80. A classificação 'médico/biológico' $x$ 'pedagógico/social' não esteve deste equívoco distante.” (PAIVA, 1994, p. 146-147)

Rigo, Ribeiro e Hallal (2011, p. 340) consideram que essa constituição histórica da EF brasileira, por apresentar esse caráter diverso de influência tanto das ciências biológicas e da saúde como das CHSOs, deve ser avaliado no sentido de perceber “[...] que tal diversidade faz parte da história da Educação Física, sendo inclusive salutar para o seu crescimento", permitindo com que esse campo busque "[...] a sua maioridade científica através de conexões, de intersecções como outras áreas do conhecimento”.

A partir dos 540 artigos identificados, os quais foram organizados em 10 eixos temáticos, e posteriormente analisados, é possível inferir que existe um grande volume de produção sociocultural e pedagógica, e essa rica diversidade se torna salutar para o crescimento da EF como campo maior.

Visualizamos, no interior do CEF, diversas comunidades ${ }^{4}$ científicas, com práticas diversas e distintas, poderes diferenciados e objetos que, por mais que aparentam serem os mesmos, têm suas abordagens completamente opostas. Sobre isso, Rezer (2014) comenta que:

Estas diferentes comunidades foram construindo, então, diferentes formas de representação para a EF brasileira, emergindo a partir de tentativas de apresentar modelos de pensamento [...] que possibilitem uma ampliação na compreensão do próprio campo, derivados de distintos aportes teóricos. (REZER, 2014, p.76)

\footnotetext{
${ }^{4}$ Por exemplo, os 13 grupos de trabalho temáticos do CBCE: Atividade Física e Saúde; Comunicação e Mídia; Corpo e Cultura; Epistemologia; Escola; Formação profissional e mundo do trabalho; Gênero; Inclusão e Diferença; Lazer e Sociedade; Memórias da EF e Esporte; Movimentos Sociais; Políticas Públicas e Treinamento Esportivo.
} 
Essas “comunidades” podem ser identificadas a partir dos 10 eixos temáticos do Quadro 2, que guardam certa similitude com boa parte dos 13 Grupos de Trabalho Temáticos do CBCE - Colégio Brasileiro de Ciências do Esporte, comunidade acadêmico-científica que congrega professores(as) da EF brasileira e latino-americana, com grande destaque na produção do conhecimento deste campo, há várias décadas. Sobre isso, Daolio (2001) considera que os estudiosos brasileiros da EF vêm buscando superar a grande influência do campo biológico no CEF, a partir da formulação de teorias e explicações que procuram ampliar a visão da própria EF: “[...] Esse processo foi e ainda é profícuo, uma vez que gera consistência teórica em uma área historicamente reconhecida apenas como de aplicação pedagógica" (DAOLIO, 2001, p. 37).

Assim, esses agentes da EF brasileira utilizaram, como embasamento das suas concretizações investigativas, os mais diversos sociólogos, antropólogos, filósofos, historiadores e pedagogos que foram (e são) de suma importância para atribuir riqueza às pesquisas, textos e proposições desta área de conhecimento, cada um com a sua contribuição em um campo empírico vasto, e que permeia EF e outros campos do conhecimento. No quadro 4, apresentamos alguns dos pensadores sociais identificados nas produções dos agentes da EF brasileira, em que os critérios de inclusão dos nomes abaixo ocorreu por recorrência quantitativa, embora reconhecemos que vários outros nomes poderiam estar incluídos no quadro:

Quadro 4: Pensadores sociais e obras comumente utilizadas pelos agentes da EF

\begin{tabular}{|c|c|}
\hline Pensador social & Principais obras identificadas \\
\hline Pierre Bourdieu & $\begin{array}{l}\text { Sociologia em Questão; Sociologia e Cultura; A Distinção: Crítica } \\
\text { Social do Julgamento }\end{array}$ \\
\hline Max Weber & $\begin{array}{c}\text { Metodologias das Ciências Sociais; Ensaios de Sociologia; } \\
\text { Sobre a Teoria das Ciências Sociais }\end{array}$ \\
\hline Theodor W. Adorno & $\begin{array}{l}\text { Introdução à Sociologia; Teoria Cultural e Teoria Popular: Uma } \\
\text { Introdução; Teoria Estética; Educação e Emancipação }\end{array}$ \\
\hline David Le Breton & $\begin{array}{c}\text { Sociologia do Corpo; } \\
\text { Adeus ao Corpo: Antropologia e Sociedade }\end{array}$ \\
\hline Michael Foucault & $\begin{array}{l}\text { Nascimento da Biopolítica; A Ordem e o Discurso; } \\
\text { Microfísica do Poder; História da Sexualidade }\end{array}$ \\
\hline Max Horkheimer & $\begin{array}{l}\text { Dialética do Esclarecimento; } \\
\text { Indústria Cultural e Sociedade. }\end{array}$ \\
\hline Norbert Elias & $\begin{array}{l}\text { O Processo Civilizatório; A Solidão dos Moribundos; } \\
\text { A Busca da Excitação; Sobre o Tempo }\end{array}$ \\
\hline Johan Huizinga & Homo Ludens \\
\hline Paulo Freire & $\begin{array}{c}\text { A importância do ato de ler; Pedagogia do Oprimido; } \\
\text { Pedagogia da Autonomia }\end{array}$ \\
\hline
\end{tabular}




\begin{tabular}{|c|c|}
\hline Eric Dunning & $\begin{array}{c}\text { Sociologia do Esporte e os Processos Civilizatórios; } \\
\text { O Fenômeno Esportivo; Futebol, Violência e Identidade Social }\end{array}$ \\
\hline Clifford Geertz & $\begin{array}{l}\text { A Interpretação das Culturas; } \\
\text { O Saber Local }\end{array}$ \\
\hline Anthony Giddens & $\begin{array}{l}\text { A Consequência da Modernidade; Modernidade e Identidade; } \\
\text { A Constituição da Sociologia }\end{array}$ \\
\hline Karl Marx & $\begin{array}{l}\text { Manuscritos Econômico-Filosóficos; } \\
\text { O Capital; A Ideologia Alemã }\end{array}$ \\
\hline Sigmund Freud & Obras Completas; O Mal Estar na Civilização \\
\hline
\end{tabular}

Fonte: Organizado pelos autores.

No Quadro 4, é possível identificar inúmeros pensadores ${ }^{5}$ vinculados às CHSO, que foram (e são) de suma importância para reafirmar e dar ênfase não somente a questões relacionadas a sua área de interesse, mas também contribuem para o crescimento e a difusão da EF brasileira, quando os relacionamos aos redirecionamentos dos nossos saberes/ fazeres a partir das Humanidades. Nesse sentido, Carvalho e Rubio (2001) enfatizam que a união de diferentes disciplinas ao redor da EF pode ser um exercício interessante do ponto de vista de quem procura o sentido e de todas as partes que estão envolvidas nessa busca por conhecimento.

Considerando a análise dos artigos feita, a partir dos textos selecionados nos principais periódicos científicos da EF brasileira a partir dos critérios anteriormente explicitados, foi possível identificar temáticas de diversas instâncias, relacionadas ao esporte, ao corpo, ao gênero, às políticas públicas, ao lazer etc., além de autores e autoras que, na sua construção teórica, operam discussões embasadas em autores da Sociologia, Filosofia, Pedagogia, História e Antropologia, que trouxeram, em suas produções, importantes e potenciais discussões, quando relacionadas ao foco principal desta pesquisa, quanto aos termos sociedade, cultura e EF.

Graças a essa diversidade e riqueza, a partir do mapa interpretativo aqui operado, foi possível considerar, a partir de tal produção levantada e analisada, que, já na segunda década do século 21, observemos na EF brasileira um intenso movimento (em aberto) de construção sociocultural do campo.

\section{Algumas notas finais}

Observamos que houve, entre 1999 a 2019, um grande volume de produção de conhecimento científico no $\mathrm{CEF}$ brasileira relacionado às temáticas veiculadas tanto à Sociologia, quanto à Antropologia

\footnotetext{
${ }^{5}$ É importante mencionar que o uso do termo "pensadores", neste caso, apenas no masculino, é porque, conforme os dados do Quadro 4, todos os citados são homens, enquanto que, no Quadro 3, dos 27 agentes da EF brasileira que mais aparecem nos artigos ou que são au tores/autoras dos textos, temos 8 representantes do universo feminino, o que também evidencia disparidades de representação de gênero no campo acadêmico-científico mundial e brasileiro.
} 
e demais extensões das CHSO. Foram identificados 2047 textos que contemplavam Cultura, Sociedade e EF, que, a partir de nossos critérios, chegou-se ao número de 540 artigos, cujo mapa interpretativo dá uma ideia dessa produção (temáticas, autores e influências teóricas e epistemológicas).

É importante considerar que, embora se evidencie o crescimento quantitativo de pesquisas e trabalhos na perspectiva sociocultural e pedagógica, ainda percebemos que os periódicos que circulam tais publicações, incluídos no Sistema WebQualis, a partir dos seus critérios de qualificação, são poucos e os mesmos já há alguns anos. Apresenta-se, então, um paradoxo: temos crescimento da produção científica, mas os locais de publicação dessa produção ainda são restritos, o que auxilia na compreensão (e denúncia) do quanto é difícil para os periódicos manterem-se estáveis (e qualificados) em meio a esse tipo de política científica brasileira, em especial àqueles e àquelas que atuam e se dedicam aos aspectos socioculturais e pedagógicos.

Considerando o nosso intento de procurar analisar como o CEF vem tematizando saberes e práticas que se relacionam enfaticamente com os conhecimentos das CHSO, observamos que o CEF foi e ainda é reinventado por suas bases de cunho biológico, embora haja, como vimos, principalmente a partir da década de 1990, um intenso e incessante trabalho na busca de conhecimento a partir de outros campos do saber, como das Humanidades, que possibilitam ampliar compreensões quanto à EF de forma geral e de seus elementos de forma particular. E, certamente, é um processo em constante movimento e com elevado grau de abertura diante das dinâmicas históricas, sociais, econômicas e culturais do contexto brasileiro (e implicações na produção científica, na formação de professores e professoras e no cotidiano escolar que envolve a concretização desses saberes e práticas).

\section{Referências}

BOURDIEU, P. Para uma sociologia da ciência. Lisboa: Edições 70, 2001.

BOURDIEU, P. O capital social - notas provisórias. In: NOGUEIRA, M.A.; CATANI, A. Escritos de Educação. 16ª ed. Petrópolis: Vozes, 2015, p. 73-78.

BRACHT, V. Saber e fazer pedagógicos: acerca da legitimidade da Educação Física como componente curricular. In: CAPARRÓZ, F.E. (org.). Educação Física escolar: política, investigação e intervenção. Vitória: Proteoria, 2001. p. 67-79.

CARVALHO, Y.M. de; RUBIO, K. (Orgs.). Educação Física e Ciências humanas. São Paulo: Hucitec, 2001.

DAOLIO, J. Educação física brasileira: autores e atores da década de 1980. Campinas: Papirus, 2001. GIL, A.C. Como elaborar projetos de pesquisa. $3^{\text {a }}$ ed. São Paulo: Atlas, 1996. 
GOLDENBERG, M. A arte de pesquisar: como fazer pesquisa qualitativa em Ciências Sociais. 9a . Ed. Rio de Janeiro: Record, 2005.

HALLAL, P.C.; MELO, V.A. de. Crescendo e enfraquecendo: um olhar sobre os rumos da Educação Física no Brasil. Revista Brasileira de Ciências do Esporte, n. 39, v.3, jul./set. 2017, p. 322-327. Disponível em: http://dx.doi.org/10.1016/j.rbce.2016.07.002. Acesso: 20 dez. 2017.

LOVISOLO, H.; VENDRUSCULO, R.; GÓIS JUNIOR, E. Recorte dos estudos socioculturais no campo da Educação Física. In: STIGGER, M.P. (org.). Educação Física + Humanas. Campinas: Autores Associados, 2015. p. 181-202.

MEZZAROBA, C. A formação e constituição de um subcampo acadêmico: a mídia-educação na Educação Física - configurações, perspectivas e inflexões. Tese (Doutorado em Educação) Universidade Federal de Santa Catarina, Florianópolis, 2018.

PAIVA, F. Ciência e poder simbólico no Colégio Brasileiro de Ciências do Esporte. Vitória/ES: Universidade Federal do Espírito Santo, Centro de Educação Física e Desportos, 1994.

PAIVA, F. Constituição do campo da Educação Física no Brasil: ponderações acerca de sua especificidade e autonomia. In: BRACHT, V.; CRISORIO, R. (orgs.). A Educação Física no Brasil e na Argentina: identidade, desafios e perspectivas. Campinas: Autores Associados; Rio de Janeiro: PROSUL, 2003. p. 63 80 .

PAIVA, F. Notas para pensar a Educação Física a partir do conceito de campo. Perspectiva, Florianópolis, v. 22, núm. esp., p. 51-82, jul./dez. 2004. Disponível em: https://periodicos.ufsc.br/index.php/perspectiva/article/view/10337 Acesso: 03 mar. 2017.

REZER, R. Educação Física na Educação Superior: trabalho docente, epistemologia e hermenêutica. Chapecó: Argos, 2014.

RIGO, L.C.; RIBEIRO, G.M.; HALLAL, P.C. Unidade na diversidade: desafios da Educação Física para o século XXI. Revista Brasileira de Atividade Física e Saúde, v.16, n.4, 2011. Disponível em: http://www.periodicos.ufpel.edu.br/ojs2/index.php/RBAFS/article/viewFile/631/661 Acesso: 02 abr. 2020. STIGGER, M.P. (org.). Educação física + Humanas. Campinas: Autores Associados, 2015.

TRIVIÑOS, A.N.S. Introdução à pesquisa em ciências sociais - a pesquisa qualitativa em educação. São Paulo: Atlas, 1995.

\section{Como citar este artigo}

MEZZAROBA, C.; LISBOA, L. V. A. Levantamento da produção sobre sociedade, cultura e Educação Física em periódicos brasileiros da Educação Física (1999-2019). Revista Kinesis, Santa Maria, v. 39, p.01-14, 2021.

* Este estudo não contou com apoio financeiro de nenhuma natureza para sua realização. 